\title{
Treatment and Outcome of Anorexia Nervosa
}

\author{
PETER DALLY,* M.B., M.R.C.P., D.P.M. ; WILLIAM SARGANT† M.B., F.R.C.P., D.P.M.
}

Brit. med. F., 1966, 2, 793-795

Five years ago one of us (W.S.) developed a new method of treatment of anorexia nervosa with large doses of chlorpromazine combined with a modified insulin regimen, and we issued preliminary reports on it (Dally and Sargant, 1960). This combined treatment appeared to be much more effective in rapidly regaining lost weight than any other treatment previously described and was easy to carry out. We have now treated over 50 patients with anorexia nervosa by this method, and they have all regained weight quickly and satisfactorily (Table I). But although regaining lost weight is an essential step in a patient's recovery this does not necessarily bring the trouble to an end. It may do so in some. But it is important to understand that several years' supportive treatment may be required after restoration of weight and that from time to time readmission to hospital is sometimes necessary.

\begin{tabular}{|c|c|c|}
\hline & Group $A(N=30)$ & Group B $(N=27)$ \\
\hline 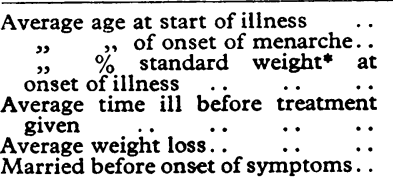 & $\begin{array}{c}19 \text { years } \\
12 \cdot 5 \text { years } \\
93 \\
16 \text { months } \\
35 \frac{1}{2} 1 \mathrm{~b} .(16 \cdot 1 \mathrm{~kg} .) \\
2\end{array}$ & $\begin{array}{c}17 \text { years } \\
13 \text { years } \\
91 \\
12 \text { months } \\
32 \mathrm{lb} .(14 \cdot 5 \mathrm{~kg} \text {.) } \\
3\end{array}$ \\
\hline
\end{tabular}

* Standard weight taken from Kemsley's (1952) tables.

In order to discover the long-term effect of this combined treatment one of us (P.D.) has followed up all our patients and compared their state now with that of a similar group treated without drugs, or treated by small doses of insulin alone. In this paper we report these findings and the value of chlorpromazine and modified insulin treatment in long-standing cases of anorexia nervosa.

\section{Selection of Patients}

Since the clear and full descriptions given by Gull (1874) and Laségue (1874) anorexia nervosa as a term has become somewhat blurred. For instance, Bliss and Branch (1960) consider all patients who have lost $25 \mathrm{lb}$. $(11.3 \mathrm{~kg}$.) or more in weight in the absence of organic disease to have anorexia nervosa, a concept so wide as to make the term almost valueless.

We looked for five essential conditions before accepting a diagnosis of anorexia nervosa: (1) refusal to eat, whether or not accompanied by anorexia ; (2) a minimum weight loss of $10 \%$ of the premorbid body-weight; (3) amenorrhoea of at least three months' duration or, if menstruation has not yet begun, a minimum age of 16 ; (4) no evidence of schizophrenia, severe depression, or organic disease; and (5) a limiting maximum age of onset of 35 .

Like Gull, we believe that males may develop a condition akin to anorexia nervosa, though this is a rare occurrence, and we agree with Ryle (1936) that a similar syndrome may develop in post-menopausal women. However, these groups are excluded by definition from this paper.

* Physician in Psychological Medicine, Westminster Hospital, London. t Physician in charge, Department of Psychological Medicine, St. Thomas's Hospital, London.

\section{Material}

Between 1957 and 1962 we treated 48 anorexia nerwosa patients with chlorpromazine and modified insulin in St. Thomas's and Westminster Hospitals. Eighteen of these patients had previously been treated elsewhere and subsequently relapsed, 11 of them having been ill for between 6 and 40 years when seen by us. Thirty patients, none of whom had been ill for more than four years, received this combined treatment as in-patients for the first time. These make up group A.

One of us (P.D.) has also examined the case histories and contacted personally or by letter all but one of 48 patients with anorexia nervosa (who conformed to our diagnostic criteria) treated by other means also at St., Thomas's and Westminster Hospitals between 1939 and 1959. Five of them had earlier received treatment elsewhere, two had discharged themselves within a fortnight against advice, a further four patients proved too difficult to manage and were transferred to mental hospitals, and one patient was discovered to have pulmonary tuberculosis. Eight patients were treated with injections of soluble insulin before meals or by a modified insulin regimen, and one even required tube-feeding. Twenty-seven patients were treated only with bed-rest and high-calorie diets (plus vitamins and a hypnotic drug at night in about half the cases), and these make up group $B$. II).

Groups A and B are comparable in their composition (Table

\section{Method and Complications}

In our earlier paper we described the method of treatment, but for the sake of completeness we include a brief account here.

Patients are put to bed at the start of treatment and it is insisted that they must stay there until they have regained a definite weight (dependent upon their age, height, body-build, and previous weight). Chlorpromazine is given by mouth, starting with as much as $300 \mathrm{mg}$. a day, and this can be increased, if necessary, by $150 \mathrm{mg}$. a day to the limit of tolerance. As much as $1,600 \mathrm{mg}$. a day has been needed in a difficult case even if debilitated physically. It is essential to increase the dose until the patient's resistance to eating is overcome ; at the same time she loses her customary sense of panic at the sight of food and the usual epigastric discomfort which follows eating. Where there is resistance to taking chlorpromazine it is better to give the drug in elixir rather than tablet form for the first week or so, to make sure it is taken. Modified insulin therapy is also begun at once, starting with 10 units each morning one hour before breakfast and progressively increasing the dose until the patient sweats and becomes drowsy. Interruption then takes place with a large meal. The average dose is between 40 and 60 units. Precautions are taken throughout the day to avoid occurrence of late hypoglycaemia. None of our patients reacted with abnormal sensitivity, though this has been thought by some to be a theoretical objection to the use of insulin in anorexia nervosa.

At first a light diet may have to be given. It includes fortified milk drinks and is steadily increased from 1,500 to 4,000 calories a day. In this way abdominal discomfort, which 
in many cases is a frequent and frightening symptom in the early stages of treatment, is minimized. The patient's confidence is gained and reassurance is constantly given, but the attitude initially should be a firm decisive one. Little attempt to uncover psychological problems is made until the patient's weight increases to near normal, when drugs are reduced in dosage or stopped ; it is most important that the patient is not allowed up until she has regained the desired weight. The majority of patients need not be taking drugs by the time they leave hospital, though antidepressants may sometimes be helpful if readjustment is difficult.

Complications were rarely troublesome or serious. Signs of Parkinsonism appeared in eight patients when large doses of chlorpromazine were, given, dyskinetic reactions involving swallowing and movements of the tongue alarmed four patients, and restlessness (akathisia) occurred in three girls. These extrapyramidal side-effects all responded quickly to anti-Parkinsonian drugs and/or reduction of the dose of chlorpromazine.

A grand-mal seizure occurred once in five patients within the first fortnight of starting treatment, and was probably caused by the large dose of chlorpromazine each was receiving. (It is of some interest, however, that $25 \%$ of our patients showed electroencephalographic abnormalities, mostly nonspecific.) Water-retention is usual in the first fortnight of treatment-so much so that pitting oedema may occur. Skin rashes occurred in three patients but responded to treatment with an antihistamine drug; in only one case was it necessary to stop chlorpromazine temporarily. Sleepiness, blurred vision, and a rather dry mouth were frequent complaints at the start of treatment. No cases of jaundice occurred. The whole treatment is surprisingly free of dangerous complications, though initially the patients can be very debilitated.

\section{Results}

Table II shows that patients in group A gained twice as much weight and left hospital sooner and heavier than patients in group $\mathrm{B}$. These differences are highly significant $(\mathrm{P}<0.01)$. That this is due largely to the effects of chlorpromazine is suggested by the finding that treatment with insulin alone is scarcely more effective than bed rest.

Treatment with chlorpromazine and insulin results in rapid increase of weight, however difficult and resistant to eating the patient may be. Table III shows the satisfactory and rapid recovery of weight that occurred in 11 cases of anorcxia nervosa continuously ill for 5 to 20 years.

Follow-up shows that one-third of both groups required readmission because of further weight loss within two years of leaving hospital (Table IV). One patient in each group died as a direct result of anorexia nervosa within a year of treatment.

\begin{tabular}{|c|c|c|c|}
\hline & $\begin{array}{c}\text { Treatment with } \\
\text { Chlorpromazine } \\
\text { and Insulin, } \\
\text { Group A }(\mathrm{N}=30)\end{array}$ & $\begin{array}{l}\text { Treatment with } \\
\text { Insulin alone } \\
(\mathrm{N}=8)\end{array}$ & $\begin{array}{c}\text { Bed Rest without } \\
\text { Specific } \\
\text { Treatment, } \\
\text { Group } B(N=27)\end{array}$ \\
\hline $\begin{array}{l}\text { Average total weight } \\
\text { gain } \because . \text { Average time in hospital } \\
\text { Average weight gain per } \\
\text { week } . \\
\text { Average } \% \text { pre-illness } \\
\text { body-weight regained }\end{array}$ & $\begin{array}{c}23 \mathrm{lb} .(10 \cdot 4 \mathrm{~kg} .) \\
36 \text { days } \\
4 \cdot 7 \mathrm{lb} .(2 \cdot 1 \mathrm{~kg} .) \\
90 \%\end{array}$ & $\begin{array}{c}18 \mathrm{lb} .(8 \cdot 1 \mathrm{~kg} .) \\
59 \text { days } \\
2 \cdot 5 \mathrm{lb} .(1 \cdot 1 \mathrm{~kg} .) \\
84 \%\end{array}$ & $\begin{array}{c}12 \mathrm{lb} .(5 \cdot 4 \mathrm{~kg} .) \\
44 \text { days } \\
2 \cdot 2 \mathrm{lb} .(1 \mathrm{~kg} .) \\
82 \%\end{array}$ \\
\hline
\end{tabular}

TABLE III.-Results with Chlorpromazine and Insulin in Patients Who Had Received Earlier Treatment

\begin{tabular}{|c|c|c|c|c|}
\hline & & & $\begin{array}{l}\text { Ill for More } \\
\text { than } 5 \text { years } \\
(\mathrm{N}=11)\end{array}$ & $\begin{array}{l}\text { Ill for Less } \\
\text { than } 5 \text { years } \\
(\mathrm{N}=7)\end{array}$ \\
\hline $\begin{array}{l}\text { Average total weight gain } \\
\text { ", time in hospital } \\
, \quad \text { weight gain per week }\end{array}$ & $\begin{array}{l}\cdots \\
\cdots \\
\cdots\end{array}$ & $\begin{array}{l}\cdots \\
\cdots \\
\cdots\end{array}$ & $\begin{array}{c}25 \mathrm{lb} .(11.3 \mathrm{~kg} .) \\
49 \text { days } \\
3.5 \mathrm{lb} .(1.6 \mathrm{~kg} .)\end{array}$ & $\begin{array}{l}26 \mathrm{lb} .(11 \cdot 8 \mathrm{~kg} .) \\
43 \text { days } \\
4.7 \mathrm{lb} .(2 \cdot 1 \mathrm{~kg} .)\end{array}$ \\
\hline
\end{tabular}

TABLE IV.-Follow-up : Readmissions

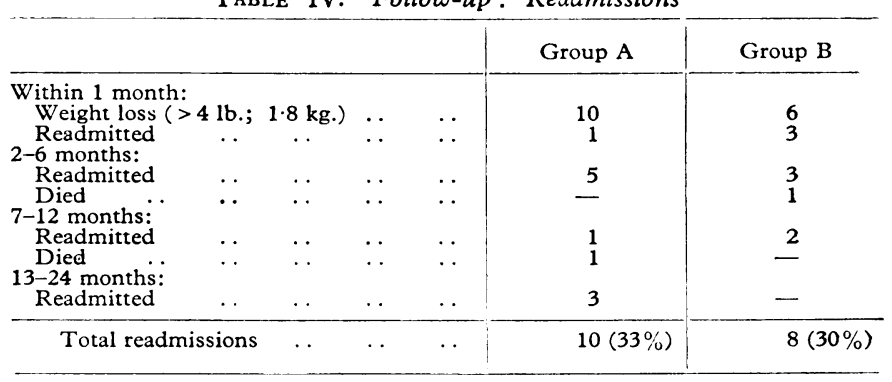

Menstruation returned after an average of 14 months in $69 \%$ of group A and of eight months in $72 \%$ of group B. Nine patients of each group have married and some of them have borne children (Table V).

Of group A $72 \%$ and of group B $60 \%$ are of satisfactory weight (within "normal" limits) and are well adjusted socially (Table VI). But fear of food or of weight increase is still present in 11 patients in group $\mathrm{A}$ and eight in group B.

\begin{tabular}{|c|c|c|}
\hline & Group A & Group B \\
\hline 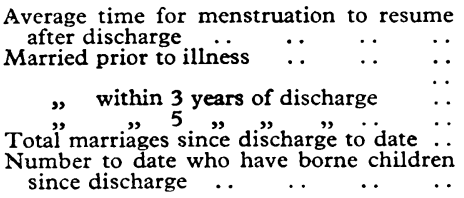 & $\begin{array}{c}14 \text { months } \\
2 \\
4 \\
8 \\
9(33 \%) \\
3\end{array}$ & 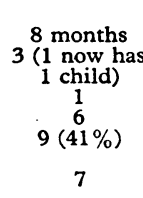 \\
\hline
\end{tabular}

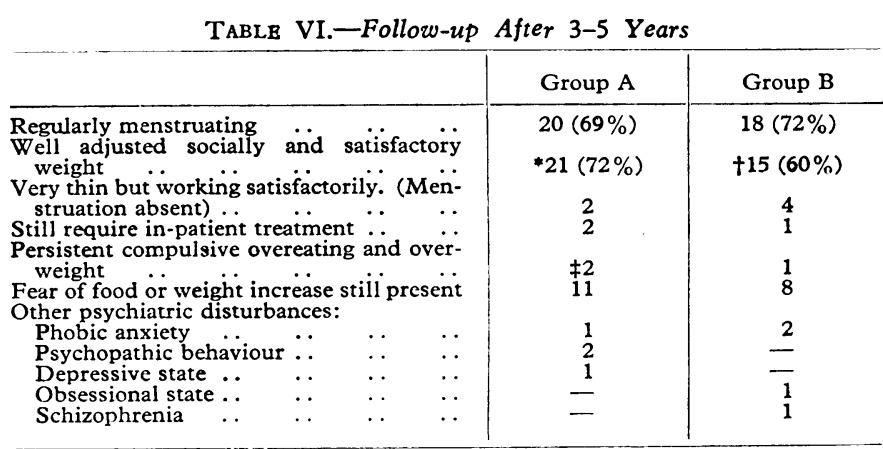

* Amenorrhoea still present in 5

tAmenorrhoea still present in 2 . †The two
behaviour.

In a small number of patients in both groups psychiatric disturbances have subsequently occurred.

\section{Discussion}

Treatment with chlorpromazine and modified insulin always resulted in a large and rapid gain in weight, however resistant initially the patient was to eating. It is a much easier treatment to carry out than the older methods. In the past, with the use of insulin alone or simply resting the patient in bed, it was sometimes impossible to achieve weight gain in the setting of a general-hospital ward; patients then had to be transferred to a mental hospital, as happened to four patients treated by bed-rest alone.

It seems probable that the important factor in this combined method is chlorpromazine, which lessens the patient's fear of and resistance to eating. Though modified insulin will increase a patient's hunger, many patients are not anorectic. When given on its own, therefore, insulin will not necessarily make the patient eat any more. However, when resistance to eating has been lowered by chlorpromazine results are excellent, and 
the combination is particularly valuable with difficult patients. But some patients' eating habits improve as soon as they come into hospital, and for them modified insulin is probably unnecessary.

It is well known that anorexia nervosa patients may lose weight again after they leave hospital and that a close follow-up is therefore important. Within one month of discharge onethird of our group A patients and one-fifth of group B had lost between 4 and $14 \mathrm{lb}$. (1.8 and $6.4 \mathrm{~kg}$.). The higher proportion of loss in group A probably reflects the greater weight gain in hospital of these patients. It is often a problem to decide when a patient should be readmitted; forcing her back into hospital too soon may in the long run do more harm than good, while delaying admission too long may be dangerous. In both groups $50 \%$ of all readmissions occurred within the first six months. All those readmitted within a month of discharge had lost around $14 \mathrm{lb}$. $(6.4 \mathrm{~kg}$.) weight, and there was little doubt about their need to return to hospital. Others lost weight slowly for several months and then precipitously, resulting in death in two instances. In some the slow but steady decline in weight continued without check and readmission was necessary after one to two years. By the end of two years 10 patients (one-third) of group A had been readmitted, four of them several times. (Half of these 10 patients have now fully recovered, three still have anorexia nervosa, and two are overweight and depressed.) Group B was similar.

From a long-term point of view there is actually no statistical difference in outcome between patients treated with chlorpromazine and modified insulin and those treated by other means; by the end of three years about two-thirds of the patients in both groups had made a satisfactory recovery. However, there is an interesting difference in the incidence of compulsive overeating (bulimia) and resulting overweight. This occurred in $45 \%$ of group A compared with $12 \%$ of group B, and may possibly be related to the use of chlorpromazine, a drug known to affect the appetite-regulating centres of the hypothalamus. Most patients who develop this symptom did so within a few weeks of leaving hospital, but some did not begin to overeat and put on excessive weight until months or years later. Chlorpromazine may increase the natural tendency for this to occur, though in the majority of patients overeating lasts only a few months. In four patients in group A, compared with one in group B, overeating was associated with compulsive stealing (kleptomania), mainly to get food.

When a patient has been ill for more than five years in spite of adequate treatment, and continues to need repeated admission, the outlook is gloomy (though one patient has recovered spontaneously after 25 years), and it is unlikely that simply restoring lost weight will have much effect. Thus of the 11 chronic anorexia nervosa patients treated with chlorpromazine and insulin eight steadily relapsed after leaving hospital in spite of outpatient follow-up treatment; chlorpromazine, antidepressant drugs, outpatient modified insulin, electric shock therapy, and intensive psychotherapy all failed to help. One of these patients died as a result of the illness. However, three patients did extremely well ; they retained their weight and resumed menstruation, and one, a married woman, became pregnant. It is significant that none of these three patients had in fact received effective treatment for the restoration of weight before being treated with chlorpromazine and insulin. This emphasizes the importance of treating anorexia nervosa patients from both physical and psychological aspects and the value of this combined treatment in difficult cases.

When this treatment fails modified leucotomy may sometimes be considered (Sargant, 1951). In very carefully selected patients results are excellent; weight is regained and stabilized, menstruation resumes, and the patient begins again, after many years of invalidism, to lead an independent enjoyable life. Results are far from satisfactory in patients who are basically " inadequate." (We hope to publish a separate report on five of our patients treated by modified leucotomy.)
Menstruation will return only when weight increases to at least $75 \%$ of standard weight and when psychological conflicts are resolved. In some patients periods returned rapidly, almost as soon as they regained their normal weight. Other patients have had to wait a long time, and in some instances periods have still not returned after many years of satisfactory weight. In general it is best to avoid treatment with hormones because, although they will usually cause temporary bleeding, menstruation will resume only when ready to do so. Failure of hormone treatment may produce quite severe reactive depression. Menstruation took almost twice as long to return, on average, in patients treated with chlorpromazine. This drug does occasionally suppress menstruation in patients not suffering from anorexia nervosa, and it is possible therefore that the drug itself is responsible for this longer delay in resuming menstruation. Return of menstruation does not necessarily indicate the end of the illness. Relapses occurred in four patients whose periods had returned spontaneously, though all subsequently recovered.

Most anorexia nervosa patients are backward in their psychosexual development and consequently have considerable conflicts over their sexual feelings and behaviour. None the less, these girls are able to marry and have children, although in some instances at least they do so in order to "be like everyone else" rather than through a more mature sense of love.

Four patients in each group developed other psychiatric symptoms. A girl in group B developed paranoid delusions, ideas of reference, and other signs of schizophrenia after 15 years of constantly relapsing anorexia nervosa (having been taking four to eight tablets of Drinamyl and an unknown quantity of thyroid extract for about a year beforehand). Pulmonary tuberculosis occurred in one patient in group B, and responded to sanatorium treatment.

\section{Conclusions and Summary}

Comparison of two similar groups of anorexia nervosa patients admitted to hospital shows the superiority of combined treatment with chlorpromazine and modified insulin regimen over other treatments in rapidly restoring lost weight. It seems likely that chlorpromazine is more important than the insulin, which can sometimes be omitted.

After discharge about one-third of patients, whatever treatment they may have received in hospital and after discharge, will lose weight and require readmission.

Compulsive overeating, resulting in the patient becoming overweight, may occur during the recovery phase, particularly after treatment with chlorpromazine. These symptoms may also be associated with stealing, usually of food.

Menstruation will return only when weight increases to at least $75 \%$ standard weight and when underlying psychological causes are resolved. The return of menstruation may be delayed longer in patients treated with chlorpromazine than in the control group.

When symptoms of anorexia nervosa persist continuously for more than five years, in spite of adequate treatment, the prognosis is poor. But if weight has never been properly restored, treatment with chlorpromazine and modified insulin may result in recovery. Modified leucotomy may be indicated in carefully selected patients long and continuously disabled by their symptoms.

\section{REFERENCES}

Bliss, E. L., and Branch, C. H. H. (1960). Anorexia Nervosa. Hoeber, New York.

Dally, P. J., and Sargant, W. (1960). Brit. med. f., 1, 1770.

Gull, W. W. (1874). Trans. clin. Soc. Lond., 7, 22.

Kemsley, W. F. F. (1952). Ann. Eugen. (Lond.), 16, 316.

Laségue, E. C. (1874). Cited by Gull (1874).

Ryle, J. (1936). Lancet, 2, 893.

Ryle, J. A. (1936). Lancet, 2, 89. 